\title{
Big data for bipolar disorder
}

\author{
Scott Monteith ${ }^{1}$, Tasha Glenn ${ }^{2}$, John Geddes ${ }^{3}$, Peter C. Whybrow ${ }^{4}$ and Michael Bauer ${ }^{*}$
}

\begin{abstract}
The delivery of psychiatric care is changing with a new emphasis on integrated care, preventative measures, population health, and the biological basis of disease. Fundamental to this transformation are big data and advances in the ability to analyze these data. The impact of big data on the routine treatment of bipolar disorder today and in the near future is discussed, with examples that relate to health policy, the discovery of new associations, and the study of rare events. The primary sources of big data today are electronic medical records (EMR), claims, and registry data from providers and payers. In the near future, data created by patients from active monitoring, passive monitoring of Internet and smartphone activities, and from sensors may be integrated with the EMR. Diverse data sources from outside of medicine, such as government financial data, will be linked for research. Over the long term, genetic and imaging data will be integrated with the EMR, and there will be more emphasis on predictive models. Many technical challenges remain when analyzing big data that relates to size, heterogeneity, complexity, and unstructured text data in the EMR. Human judgement and subject matter expertise are critical parts of big data analysis, and the active participation of psychiatrists is needed throughout the analytical process.
\end{abstract}

Keywords: Bipolar disorder, Big data, EMR, Registries, Claims, Patient monitoring

\section{Background}

The frequency and importance of comorbid mental and chronic physical illness have emphasized the need for a change in the delivery of psychiatric care, including bipolar disorder (Melek et al. 2014, DeHert et al. 2011). Bipolar disorder is associated with poor functional outcome (Conus et al. 2014), considerable economic cost for society (Kleine-Budde et al. 2014; Young et al. 2011), and management is often complicated by medical comorbidity such as type II diabetes/insulin resistance (Calkin et al. 2015; Calkin and Alda 2015; Carney and Jones 2006). Responses to improve care delivery include integrating psychiatry with primary care (Butler et al. 2008; Manderscheid and Kathol 2014; Cerimele and Strain 2010; Katon et al. 2010), collaborative care measures (Woltmann et al. 2012), implementing preventive programs and quality measurements consistent with a population health perspective (Rose 2001; Mabry et al. 2008), and increasing emphasis on the genetic and neuroscience

\footnotetext{
*Correspondence: michael.bauer@uniklinikum-dresden.de

${ }^{5}$ Department of Psychiatry and Psychotherapy, Universitätsklinikum Carl Gustav Carus, Technische Universität Dresden, Fetscherstr. 74, 01307 Dresden, Germany

Full list of author information is available at the end of the article
}

basis of mental illness (Insel 2009; Reynolds et al. 2009). Additionally, precision medicine initiatives are accelerating interdisciplinary research with a goal of tailoring psychiatric care to the individual (Insel 2014).

Big data and advances in the ability to analyze these data are fundamental to this evolving perspective of psychiatry (Monteith et al. 2015; NRC 2013). Big data can be conceptualized as heterogeneous data, unprecedented in size and complexity, lacking in structure, and coming from many sources (Monteith et al. 2015). The scale of big data in size and complexity makes it difficult to process, analyze, and extract useful information (Burkhardt 2014). Today, the primary source of big data in medicine is from providers and payers including electronic medical records (EMR) created by physicians, claims records, pharmacy records, and imaging. However, the data for analysis will keep expanding from omics, such as genomic, epigenomic, proteomic, and metabolomic data. Today, about $95 \%$ of the data for each patient is generated by imaging (Hamalka 2011), and genomic data requires 50 -fold greater storage per patient than imaging (Starren et al. 2013). Data will also be coming from non-traditional sources including patients and non-providers, from smartphone applications, sensors, and Internet activities 
(Glenn and Monteith 2014a). With the addition of data from patient devices, it is estimated that every person will generate more than 1 petabyte ( 1 million gigabytes) of health information over a lifetime (IBM 2015a). IBM envisions a future in which 10 percent of medical data will be from medical records, 20 percent from genomics, and $70 \%$ from patient-created sources (Slabodkin 2015). The amount of medical-related data in existence is expected to double in size every 2 years (IBM 2015b).

It is still early in the process of converting from paper to digital-based medicine. As with other industries, the main benefits will be related to future innovations and redefined work processes fostered by the technology, and increased software usability and usefulness (Fernald and Wang 2015; Landauer 1995). However, many initial benefits from digitizing data are already being seen today in the analysis of very large databases. The objective of this review is to discuss both the promises and challenges of using big data to improve the understanding and treatment of bipolar disorder.

\section{Data sources from providers and payers}

There are many public and private sources of big data from EMR, claims/administrative data, and registries that are available for secondary use in medical research. These data sources were not designed for research and each has strengths and weaknesses, with differences in quality, completeness, and potential for bias. In the US, claims or administrative encounter data that providers (physicians, hospitals, labs, and pharmacies) submit for payment to insurers and the government provide the most complete picture of patient involvement with the healthcare system. Although standardized diagnostic and procedure codes are used, claims data lacks clinical detail such as test results. The diagnosis on a claim is only for the services performed on that date, and may be incorrect, incomplete, differential, or driven by reimbursement policies (Sarrazin and Rosenthal 2012; Wilson and Bock 2012; West et al. 2014; Overhage and Overhage 2013). The time lag for claims processing is often several months. About $17 \%$ of commercially insured people in the US switch coverage each year posing challenges for longitudinal analysis (Sung 2015; Marketscan 2011).

In contrast to claims, EMR provide timely clinical details from the providers who use the software, especially related to patient management. The clinical data may include patient history and symptoms, multiple diagnoses including those unrelated to the current visit, physician assessment and treatment plan, disease severity, lab results, vital signs, non-prescription drugs and results of screening tools such as PHQ-9. Government mandates in the US have dramatically increased the use of EMR. About half of EMR text is unstructured data
(Davenport 2014), and many challenges remain to automatically extract information from the rich but distinct vocabularies used throughout medicine (Dinov 2016; Ivanovic and Budimac 2014). Efforts are underway to address standardization with the goal of semantic interoperability of data from different providers and software systems (IHE 2015; HealthIT.gov 2015; Dinov 2016). There are other important quality issues in EMR data including inconsistency, redundancy, inaccuracy, missing data, interoperability between vendor products, and potential biases from measured and non-measured confounders (Monteith et al. 2015; Bayley et al. 2013; Kaplan et al. 2014; Hersh et al. 2013; Hripcsak et al. 2011).

Outside the US, psychiatric register data may be based on a country population such as in the Nordic countries or Taiwan, or a geographical area such as the South London and Maudsley NHS Foundation Trust (SLAM) case register, or a provider (Munk-Jorgensen et al. 2014; Allebeck 2009; Stewart et al. 2009). These registries provide a longitudinal record of all psychiatric contacts, and have high coverage and low dropout rates in countries with a national health service. However, there are limitations to the validity and quality of data in psychiatric registries, including over-representation of severe cases or inpatient data, sparse clinical detail, exclusion of variables not available from all institutions reporting to the register, and insufficient linking to other registries such as cause of death (Munk-Jørgensen et al. 2014). There are also questions about the validity of psychiatric diagnoses in the register data (Byrne et al. 2005; Øiesvold et al. 2013), including bipolar disorder (Øiesvold et al. 2012). Psychiatric case registries do not include patients without a psychiatric diagnosis for comparison (Munk-Jørgensen et al. 2014). Some other types of registries that can be linked to psychiatric registries include those for general health, prescription drugs, vital statistics, school registries, social insurance registries, and biobanks (Allebeck 2009), each of which has strengths and weaknesses.

Other sources of data include research databases and surveys, such as the US National Comorbidity Survey (Kessler et al. 1994) or the National Epidemiological Survey on Alcohol and Related Conditions (NESARC) (Grant et al. 2004), which may have a national scope but contain a subset of clinical information.

Even very large databases containing millions of individuals may not be representative of the general population (Riley 2009). For example, the US claims/ administrative data from a Medicaid population will include more younger women and children, data from an employer-offered HMO may include more younger and healthier people, and data from Veterans Affairs (VA) will include mainly males and be older (Overhage and Overhage 2013; Medicaid 2015). In a US multistate 
EMR database with 84 million patients, psychiatric and behavioral diagnoses were less frequent as compared to the US National Inpatient Sample, an established population estimate based on claims (HCUP 2015; DeShazo and Hoffman 2015). Population-based registries from small homogenous countries may not be representative of the population in larger diverse countries. Due to the heterogeneity among very large databases, the data source selected may challenge the results of observational studies, including even finding contradictory statistical significance (Madigan et al. 2013; Goldstein and Winkelmayer 2015; Crump et al. 2013a). However, with a clear understanding of the strengths and weaknesses of a database, some findings from observational analyses can now be verified in many national and regional settings. For example, in a systematic review of 25 international population or community-based studies using different diagnostic criteria, the prevalence of bipolar disorder type I and type II was consistently low (Clemente et al. 2015).

The addition of complementary data sources may improve the accuracy and usefulness of data from any one source. Even when using validated algorithms, it is difficult to determine an episodic diagnosis such as depression when analyzing US claims data, and combining another data source such as EMR may improve accuracy (Townsend et al. 2012; Fiest et al. 2014). However, in the US, linking of data from unrelated sources that were de-identified to meet privacy regulations is challenging (West et al. 2014, Li and Shen 2013). In contrast, many European countries have a unique person identifier that is present on all medical data (Allebeck 2009). The use of complementary linked databases may also expand the types of research questions that may be addressed. Examples of useful linkages include register population data linked with biobank data in a study that found no association between markers of prenatal infection and the risk of bipolar disorder (Mortensen et al. 2011), and in a study that found elevated C-reactive protein was associated with an increased risk of late-onset bipolar disorder (Wium-Andersen et al. 2015).

\section{Uses for data from providers and payers}

The analysis of very large databases has provided fundamental information about bipolar disorder including the incidence, prevalence, decreased life expectancy (Munk-Jørgensen et al. 2014; Allebeck 2009; Laursen et al. 2007; Chang et al. 2011; Kessing et al. 2015c; Kessing et al. 2015d), and trends in prescribing medication (Baldessarini et al. 2007; Hayes et al. 2011; Bjorklund et al. 2015). Results from the analysis of large data sources are continuously being incorporated into patient care and research, and some key areas are discussed below.

\section{Health policy decisions}

Health policy decisions focus on outcome and cost. Big data is fundamental to the increasing importance of clinical guidelines, defining and measuring metrics that reflect the quality of care delivered, and meeting performance standards based on quality metrics. For the treatment of bipolar disorder, big data studies are helping to characterize problems and evaluate the results of policy changes. Of great concern are repeated findings of excess mortality in patients with bipolar disorder due primarily to physical illness, and of continuing disparities in the treatment of physical illness as compared with the general population (Roshanaei-Moghaddam and Katon 2009; McGinty et al. 2015). Some examples of suboptimal care for medical illness for people with bipolar disorder found using big data are shown in Table 1. In addition to health services and physical illness, socioeconomic factors and patient behaviors contribute to excess morbidity and mortality in bipolar disorder (Druss et al. 2011). The linking of psychiatric data with other databases, such as government financial databases, will help to clarify the complex, cumulative impacts of diverse socioeconomic factors, as shown in Table 2. Examples of studies directly related to health policy and bipolar disorder using big data are given in Table 3.

\section{Evaluation of rare events}

Big data allows the study of rare events and outcomes that may require data from multiple sources to provide an adequate sample size for detection. Randomized controlled trials are not powered to detect rare events or long-term effects, and case control and retrospective cohort study designs of observational databases collected from clinical practice are often used (Chan et al. 2015; Rodriguez et al. 2001). For example, there have been several recent large or population-based studies of renal related events in patients who were treated with lithium, as shown in Table 4. Big databases are being used for pharmacovigilance of many drugs prescribed for bipolar disorder, such as studies of the potential for antipsychotics to increase risk of a seizure (Bloechliger et al. 2015), pulmonary embolism (Tournier 2015; Conti et al. 2015), and a Torsades de pointes ventricular arrhythmia (Poluzzi et al. 2013).

\section{Exploration and hypothesis generation from large databases}

The exploration of big data offers unique opportunities to find correlations that may trigger the investigation of new areas and generation of new hypotheses (Varian 2014; Khoury and Ioannidis 2014). These new correlations may or may not have meaning, do not measure causality, and may be further investigated by traditional 


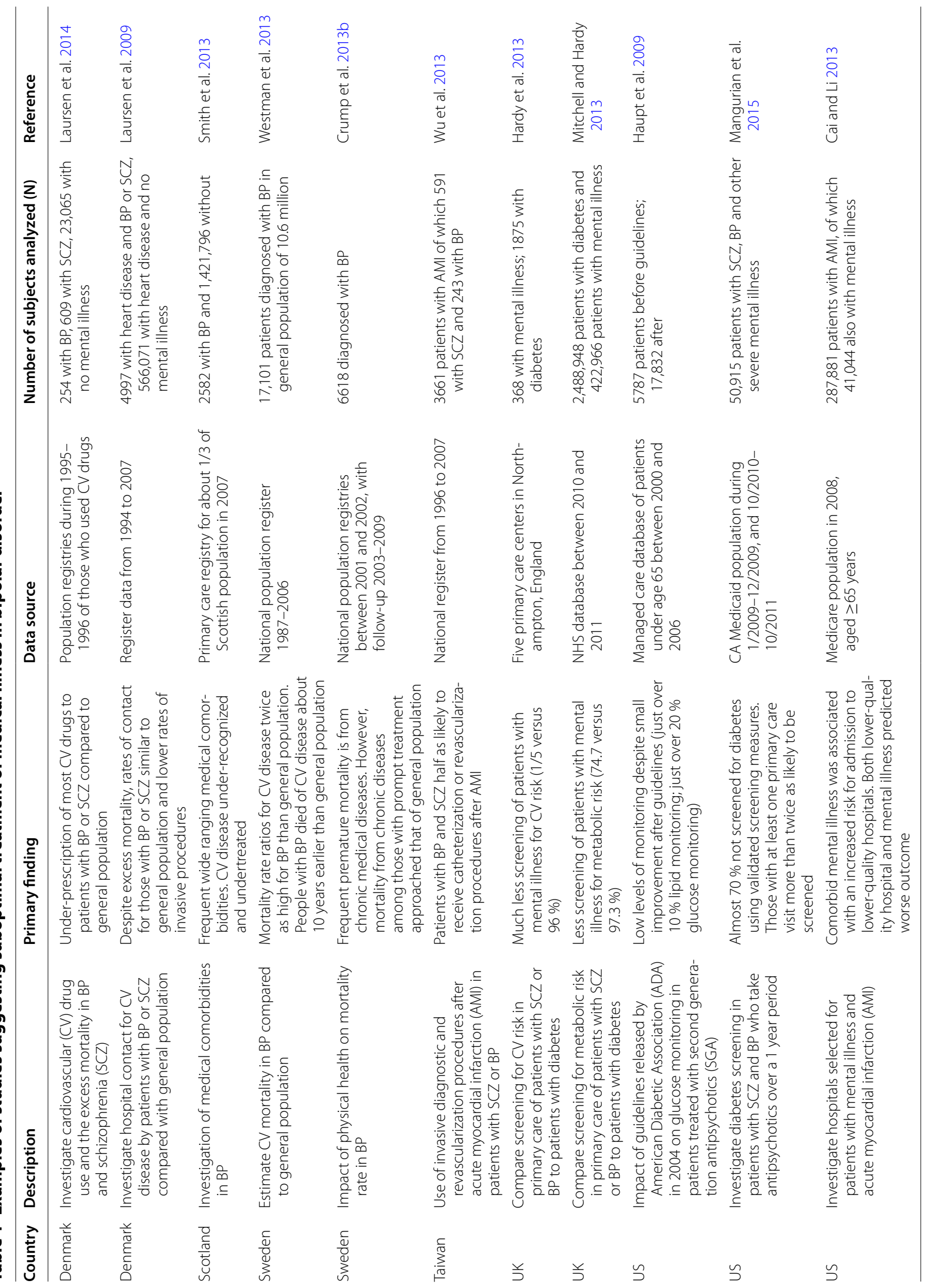


or data-intensive experimental methods as appropriate. There are many computational and statistical challenges associated with the analysis of big data related to the number of patients, number of variables per patient, and the quality and technical complexity of the databases (Monteith et al. 2015; Fan et al. 2014; Grimes and Schulz 2002). Both the variables included and the analytic techniques used may lead to variation in the associations detected in big data studies (Abrams et al. 2008; Fan et al. 2014; Patel et al. 2015a).

Additional correlations detected include an association between epilepsy and bipolar disorder (Wotton and Goldacre 2014; Clarke et al. 2012), an increased risk of pneumonia in patients with bipolar disorder taking antipsychotics (Yang et al. 2013), an increased risk of bipolar disorder in those with a diagnosis of autism spectrum disorder (Selten et al. 2015), and finding that the premature risk of cardiovascular disease in bipolar disorder is not explained by traditional risk factors including cigarette smoking, obesity, or hypertension (Goldstein et al. 2015). In a study using medical records from 110 million patients, new associations were found between Mendelian diseases and complex psychiatric diseases, including bipolar disorder (Blair et al. 2013).

\section{Defining phenotypes}

There is considerable interest in using EMR to automate the process of defining phenotypic cohorts for genetic studies of bipolar disorder, since sample sizes of tens of thousands are needed (Pathak et al. 2013; Potash 2015). In addition to the study of phenotype-genotype relationships and gene-disease associations, phenotypic cohorts will enable a wide range of clinical research. Despite many challenges, semi-automated methods are now being used to define phenotypes from EMR for psychiatric disorders, including bipolar disorder (Lyalina et al. 2013; Castro et al. 2015a). The methodology used to automate phenotype detection in EMR is evolving, and includes data mining, natural language processing, statistical techniques, and human expertise (Hripcsak and Albers 2013; Pathak et al. 2013). More standardization is expected in the future.

\section{Predictive models}

Predictive models are widely used in medicine, such as cardiovascular risk prediction, to estimate the presence of a diagnosis or event, or if the diagnosis or event will occur in a specific time period (Moons et al. 2012). The results of validated predictive models may assist the physician and patient with decision making to mitigate risks, and help to limit spending on unnecessary procedures. Before adoption for clinical use, predictive models require considerable testing and re-adjustment, including internal validation, external validation with other populations, followed by determination if the validated model provides actionable information to the clinician and patient (Moons et al. 2012). Most predictive models are based on a small number of variables collected in cohort studies such as the Framingham Heart Study (D'Agostino et al. 2008). In general, models used in medicine today have limited predictive power, and access to the large number of variables and patients in EMR and other databases may improve their accuracy in the future (Berger and Doban 2014; de Lissovoy 2013). With the frequent use of heuristics in medical decision making, complex predictive models also need practical input requirements for routine use in clinical situations (Marewski and Gigerenzer 2012).

Many technical issues impede the development of predictive models from EMR data, including quality, multidimensional complexity, bias, comorbidities, and confounding medical interventions (Paxton et al. 2013; Wu et al. 2010; Wang et al. 2014). The temporal nature of EMR data also poses a significant challenge for prediction (Singh et al. 2015; Binder and Blettner 2015). In contrast to a controlled longitudinal study, data entries into an EMR only occur when a patient initiates or a physician recommends and documents care. There are great differences in the time between visits for one patient, and across all patients, in the number of visits and length of time each patient is tracked. New variables detected in EMR data may be associated with but not predictive of disease (Ware 2006). A variety of machine learning, data mining, classification algorithms, and statistical approaches are currently being researched for the future (Singh et al. 2015; Wu et al. 2010, Wang et al. 2014).

While the primary benefits of prediction will be in the future, in some recently developed models, bipolar disorder is a risk factor for readmission to a psychiatric hospital within 30 days of discharge (Vigod et al. 2015), readmission to a safety-net hospital within a year (Hamilton et al. 2015), and suicide by veterans (McCarthy et al. 2015). The addition of variables relating to a diagnosis of bipolar disorder or schizophrenia improved the accuracy of a predictive model of cardiovascular risk for those with these diagnoses (Osborn et al. 2015).

\section{Data sources from patients and non-providers}

Digital technologies that are widely accepted by the general public are being integrated into the routine care of bipolar disorder to increase patient involvement and expand clinician oversight between visits. Many technologies are suitable platforms for active or passive patient monitoring including computers, smartphones, and even clothing with embedded sensors. Today, the patient-created data are not generally integrated into the EMR. 


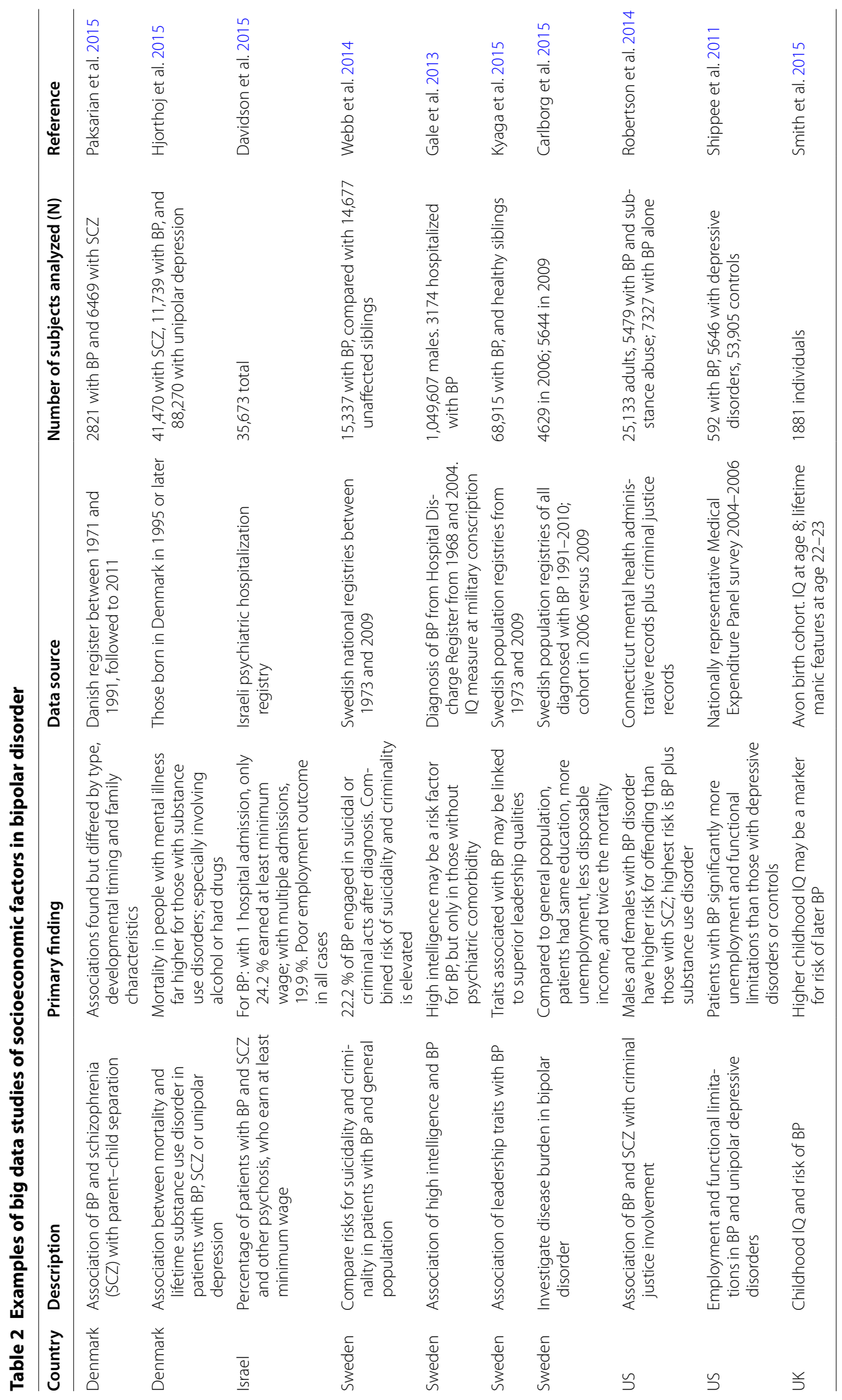




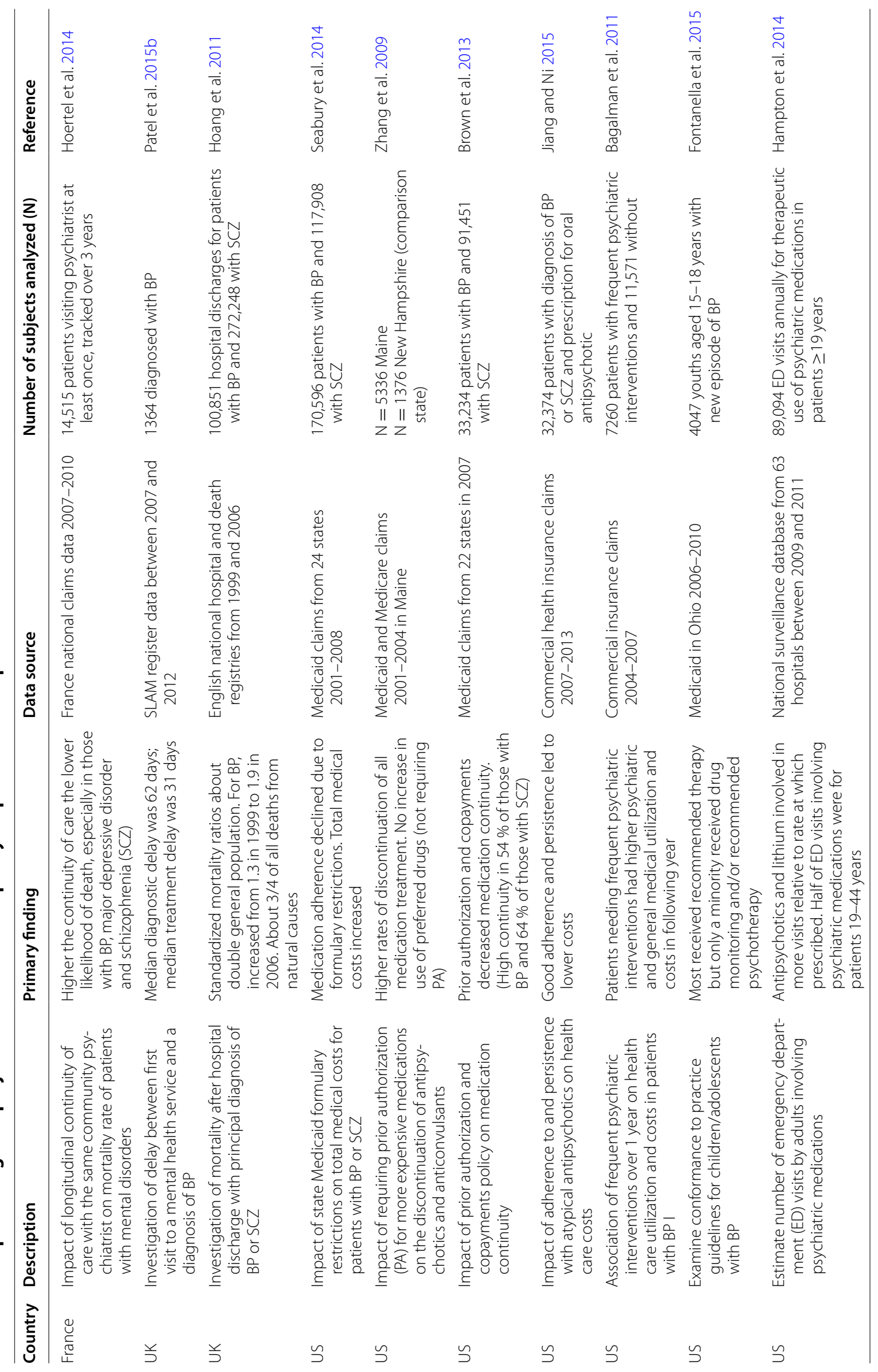




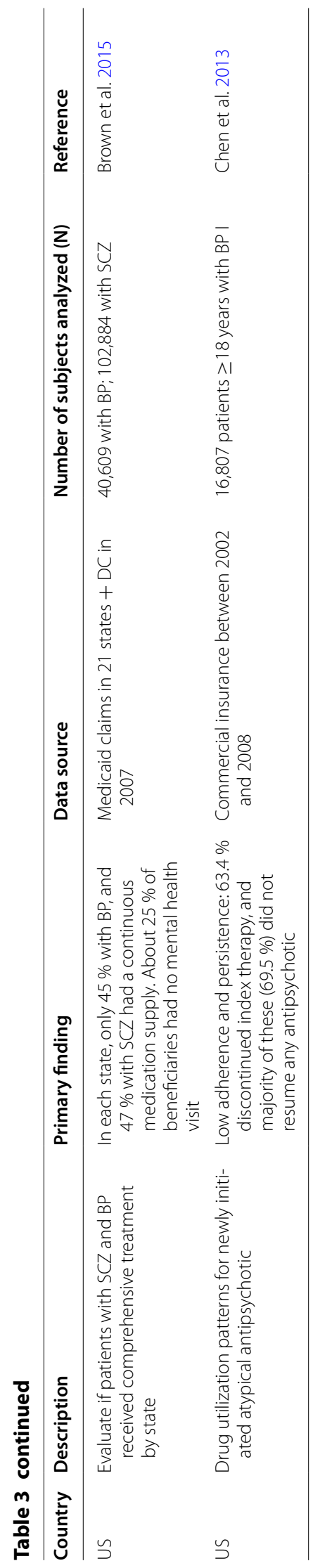




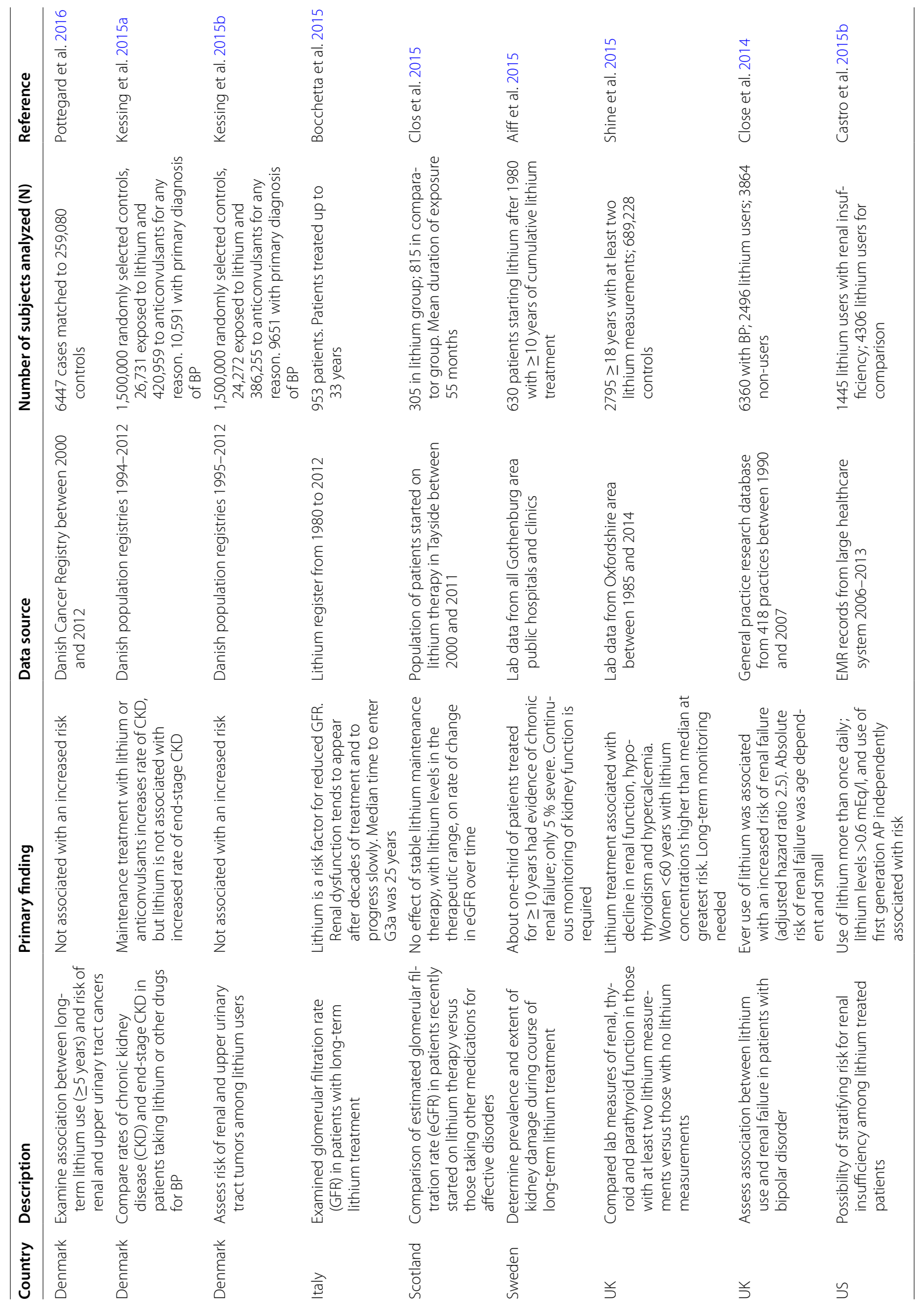




\section{Data actively created by patients outside of medical settings}

Many applications are available today to monitor bipolar disorder away from medical settings that require active patient participation. These include validated products for mood charting such as the ChronoRecord on a computer (Bauer et al. 2004; Bauer et al. 2008), the Life-Chart on a smartphone and web site (Scharer et al. 2015), weekly text messaging of responses to Quick Inventory of Depressive Symptomatology and Altman self-rating manic scale (Bopp et al. 2010), and weekly or monthly use of an interactive voice response (IVR) system to complete the PHQ-9 (Piette et al. 2013). In all cases, the patients respond to questions or prompts directly related to their illness. In addition to clinical use, data collected from these systems is often aggregated for research (Bauer et al. 2013a, 2013b; Moore et al. 2014). A large number of parameters may be accumulated for each patient, such as from daily medications taken (Bauer et al. 2013a), but data are not routinely integrated into the EMR. Although challenges remain regarding the interpretation of self-reported data, much of the understanding about the long-term course of bipolar disorder is due to the daily recording efforts of patients worldwide, starting with paper-based instruments (Bauer et al. 1991; Kupka et al. 2007).

\section{Data passively created by patients outside of medical settings}

With passive monitoring, patients do not directly provide information about their illness, and much of the data collected are non-medical. For example, data from Internet and smartphone activities, and from sensors in smartphones and wearable technology, are routinely being used to monitor mental state and behavior for nonmedical purposes such as behavioral advertising (Glenn and Monteith 2014b; Geller 2014; FTC 2009). There are a variety of passive monitoring projects for bipolar disorder, mostly in the pilot phase, with examples shown in Table 5. The implementation of routine passive monitoring for large numbers of patients faces many hurdles, including patient acceptance, physician usability, and processing large volumes of data from sensors (Redmond et al. 2014; Muench 2014). Many passive monitoring projects involve smartphones. Both the differing physical characteristics of the standard devices available to consumers such as sensor accuracy and memory size, and methods selected for analysis may impact the findings (Banaee et al. 2013; Redmond et al. 2014). The sales of smartphones are flat in developed countries with saturation reached, and usage patterns vary among countries (Thomas 2014, Waters 2015). In the US in 2015, 64\% of adults in the US use a smartphone with $7 \%$ relying primarily on it for Internet access (Smith 2015).

\section{Commercial processing of data}

Provider-created data are traditionally processed by the provider or their contractors. In contrast, commercial firms unrelated to medicine may be involved in both active and passive patient monitoring. Many behavioral related apps are available for Apple and Android smartphones, and commercial firms may receive, store, and analyze data using proprietary and unvalidated algorithms. Any potential combination of data processed by commercial firms with EMR data needs to be carefully evaluated as the firms may not be covered by national privacy regulations (Glenn and Monteith 2014b). An analysis of 79 mobile health apps certified as trustworthy by the UK NHS found a multitude of privacy and security flaws (Huckvale et al. 2015).

\section{Changing world of technology}

Passive monitoring should be considered in the context of the ongoing changes in digital technology, especially in relation to mobile devices for consumers. First, the devices used to access the Internet will change the online activities of the public. For example, the use of a search engine is much lower from a smartphone than from a computer (Arthur 2015; MacMillan 2015). Second, the widespread use of mobile technology has triggered a push toward developing artificial intelligence (AI) interfaces for devices, as evidenced by the near simultaneous announcements of open source AI software tools from Google, Microsoft, IBM, and Facebook (Simonite 2015). The vision of Larry Page of Google is for Google to tell you what you want before you ask the question (Varian 2014, Page 2013). In an international survey of 6600 smartphone users by Ericsson, half of all smartphone users expect AI interfaces to replace the smartphone screen within 5 years, and one-third want AI to keep them company (Boulden 2015). Messaging chatbots (computer-generated responses based on AI) are starting to replace search engines on mobile devices (Elgan 2015). In the future, consumer mobile devices will routinely incorporate voice and gesture input, and as hardware features change, the AI algorithms will also evolve. In the background, there is an industry-wide effort to develop AI algorithms based on massive databases to predict behavior and emotions for uses such as for targeted marketing.

\section{Other provider data sources}

Massive amounts of data will be coming from genomics, proteomics, and image processing, and the ongoing efforts of large-scale consortia will help to elucidate the neuropathology of bipolar disorder and define new treatment targets. The ENIGMA Consortium detected subcortical brain volumetric changes using brain structural 
MRI scans from 1710 patients with bipolar disorder and 2594 controls (Thompson et al. 2014, Hibar et al. 2016). The ConLiGen Consortium identified genetic variants associated with lithium response in a GWAS study of 2563 patients with bipolar disorder (Hou et al. 2016). The Psychiatric Genomics Consortium (PGC) found a new susceptibility locus in a GWAS study of 7481 individuals with bipolar disorder and 9250 controls (Sklar et al. 2011). Recent technology allows large-scale comparison of proteome profiles (Gold et al. 2010; SomaLogic 2016), and findings may improve predictive models for bipolar disorder. These data are not expected to be incorporated into the EMR or impact the routine care of bipolar disorder in the near future but suggest future directions for data integration.

\section{General considerations}

There are a wide range of anticipated and unanticipated complications related to the use of big data in the study of bipolar disorder some of which are mentioned briefly below.

\section{Privacy and confidentiality}

The privacy and confidentiality of big data are a major concern. Many technical issues affect the privacy and confidentiality of big data related to hardware and software implementations, mobile devices and wireless networks, shared resources, and shared control over monitoring systems (Ko et al. 2010). Breaches of provider medical data occur frequently with about $90 \%$ of health care providers reporting at least one data breach over the last 2 years in an international study in 2015 (Experian 2015). The use of commercial apps for monitoring also complicates privacy issues. Patients may incorrectly assume that national medical privacy regulations apply to data collected and processed by non-providers (Glenn and Monteith 2014b). Patient posting of private medical data online, such as in support groups, is another complication, and online data cannot really be deleted due to the distributed and redundant storage of Internet data (President's Council 2014). Preserving privacy in big data research is particularly difficult, since this often includes multiple international collaborators, and data are copied and shared around the world. The legal framework for medical privacy varies among countries (Dove and Phillips 2015).

\section{Ethical considerations}

There is disagreement about the importance of informed consent for big data research (Rothstein 2015), with some wanting to ease regulations (Larson 2013). The consent process is of particular importance for bipolar disorder due to the highly sensitive information in the EMR
(Clemens 2012), and since some patients have cognitive impairment (Daglas et al. 2015).

De-identification is frequently used to protect individual privacy. De-identified data are not covered by US federal privacy laws and are sold commercially. Yet the general public cares about using de-identified data without consent (McGraw 2013), and about the specific purpose for secondary use (Grande et al. 2013). The released data may be vulnerable to re-identification since current de-identification methods are inadequate for high-dimensional data (Narayanan et al. 2016). There is a growing confluence of the interests of academic and commercial organizations in big data projects, leading to questions about ownership of the data and any benefits created, and about disposition of data if a firm goes out of business or is purchased.

In countries without a national health service, predictive models of costs may increase coverage disparities of vulnerable groups (Wharam and Weiner 2012). Predictive models being developed by commercial, non-medical companies can create ethical conflicts (Glenn and Monteith 2014a). For example, privacy and non-discrimination laws in the US that impact decisions about credit, employment, or housing do not prohibit discrimination against the predisposition of disabilities (Horvitz and Mulligan 2015).

\section{Unreasonable expectations for predictive models}

The expectations of the general public regarding predictive models may be inappropriate. People are familiar with personalized recommendations from Netflix or Amazon, search results from Google, and advertising on Apple and Android smartphones. These predictive models are based solely on the available data, are unconnected to causal inference and underlying mechanisms, and focus on predicting the present rather than the future (Hand 2013; Curtis 2014). The validity of predictive models in business is judged by increased overall sales and profits, not by accuracy of the prediction for individual customers (McAfee et al. 2012).

Physicians may also have unrealistic expectations for models that predict behavior based on big data. Big data is non-sampled, and from sources with a purpose other than statistical inference (Horrigan 2013). Data that are created and collected by humans reflect physical place and culture, and contain hidden biases (Pope et al. 2014, Crawford 2013). More data does not necessarily improve predictions over those made using smaller datasets as data must be relevant to the question at hand (Monteith et al. 2015; Guszcza and Richardson 2014). Big data is also without context (Boyd and Crawford 2012; Bilton 2013). Furthermore, malware or denial of service attacks occur frequently, change overall Internet 


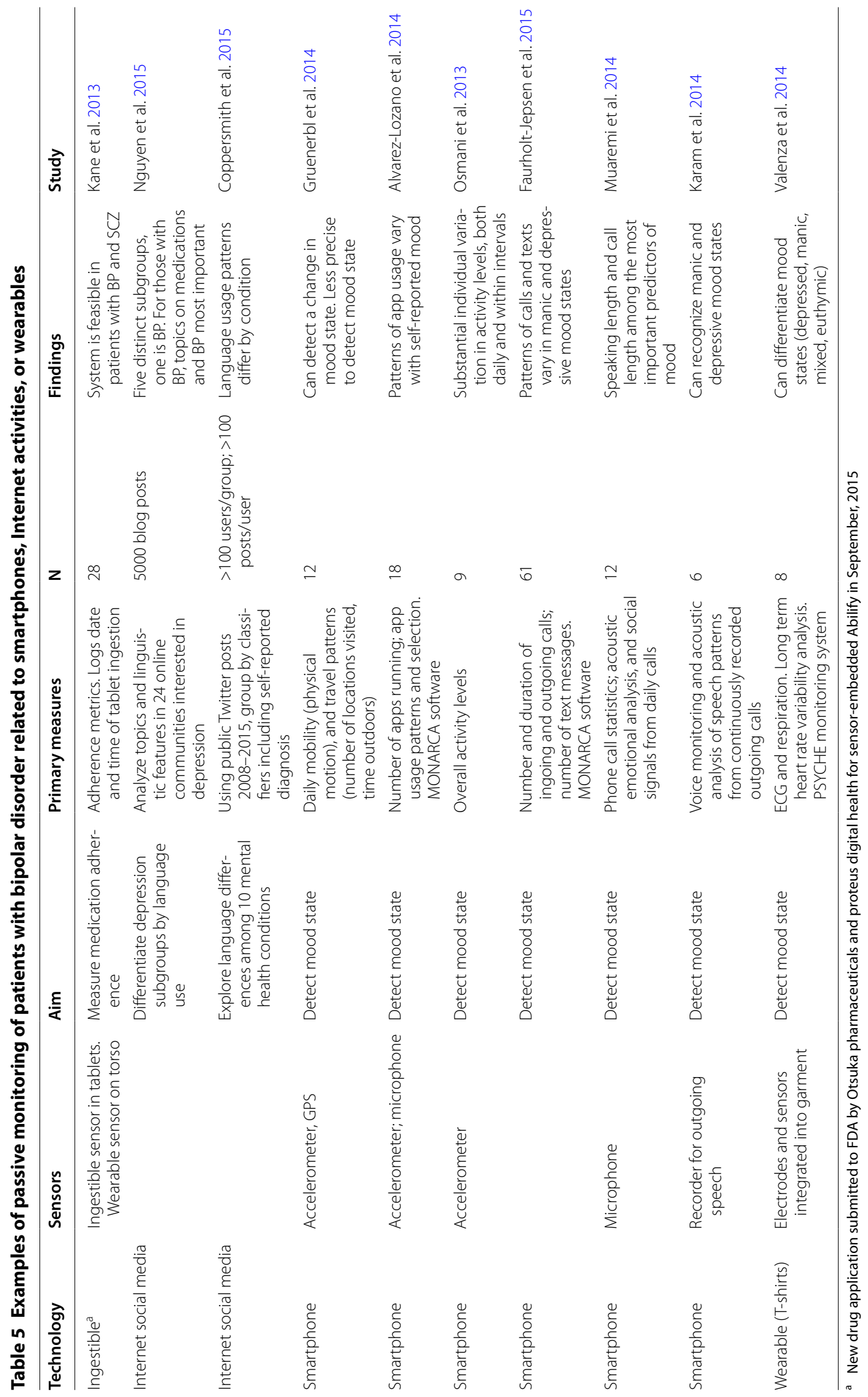


behavior patterns, and further complicate interpretation of human behavior (NRC 2013). Predictive models can be wrong as shown repeatedly with Google Flu (Lazer et al. 2014a, b). Predictive models in medical and related settings can be inconsistent and biased (Singh et al. 2014), have little clinical impact (Hochster and Niedzwiecki 2016), and may be most appropriate for health policy and risk stratification rather than individual risk prediction (Harris et al. 2015; Wray et al. 2013; Wharam and Weiner 2012).

\section{Analytical challenges}

In the future, data from all provider and patient sources will be integrated, creating massive datasets for analysis. Massive datasets have issues of scale, heterogeneity, multidimensional complexity, error handling, privacy, provenance, and many types of biases (NRC 2013; Monteith et al. 2015). If analysis of big data is based on the classical methods, underlying assumptions are likely to be violated. Researchers with different backgrounds tend to have different perspectives on data analysis, using either statistical (model-based focus on variability) or algorithmic (data mining for patterns and rules) (NRC 2013; Mahoney et al. 2008) techniques. New algorithms for big data are combining the complementary strengths of both approaches.

Human judgment is an absolutely critical component of big data analysis (Wyss and Stürmer 2014; NRC 2013). To optimize the studies of big data for bipolar disorder, participation of those with expertise in psychiatry is required throughout the analytical process, such as for parameter selection and exclusion, interpretation of results, and hypothesis generation. For example, just as Captcha demonstrates the difference between human and machine image resolution (Datta et al. 2009), psychiatrist input is needed during the development of algorithms to interpret the use of language by those with bipolar disorder.

\section{Conclusions}

Big data projects based on the data collected by providers in EMR, claims, registries, and active patient monitoring are providing valuable information on many aspects of bipolar disorder for research and clinical care. In the near future, data from passive patient monitoring will be available and integrated with the EMR, and diverse data sources from outside of medicine such as government financial data will be linked for research. This is only the beginning. Further on, data from genetics, other omics, and imaging will also be integrated with the EMR, and lead to new levels of understanding and improvement in routine care. Many significant challenges remain for big data projects, and the active collaboration of psychiatrists is required throughout the analytical process. Big data will provide the basis for transforming the understanding and management of bipolar disorder.

\section{Authors' contributions}

Authors SM and TG were involved in the draft manuscript. All authors contributed to the final manuscript. All authors read and approved the final manuscript.

\section{Author details}

${ }^{1}$ Michigan State University College of Human Medicine, Traverse City Campus, 1400 Medical Campus Drive, Traverse City, MI 49684, USA. ${ }^{2}$ ChronoRecord Association, Inc, Fullerton, CA 92834, USA. ${ }^{3}$ Department of Psychiatry, Warneford Hospital, University of Oxford, Oxford OX3 7JX, UK. ${ }^{4}$ Department of Psychiatry and Biobehavioral Sciences, Semel Institute for Neuroscience and Human Behavior University of California Los Angeles (UCLA), 300 UCLA Medical Plaza, Los Angeles, CA 90095, USA. ${ }^{5}$ Department of Psychiatry and Psychotherapy, Universitätsklinikum Carl Gustav Carus, Technische Universität Dresden, Fetscherstr. 74, 01307 Dresden, Germany.

\section{Competing interests}

The authors declare that they have no competing interests.

Received: 12 February 2016 Accepted: 23 March 2016

Published online: 11 April 2016

\section{References}

Abrams TE, Vaughan-Sarrazin M, Rosenthal GE. Variations in the associations between psychiatric comorbidity and hospital mortality according to the method of identifying psychiatric diagnoses. J Gen Intern Med. 2008;23:317-22

Aiff H, Attman PO, Aurell M, Bendz H, Ramsauer B, Schön S, et al. Effects of 10-30 years of lithium treatment on kidney function. J Psychopharmacol. 2015;29:608-14

Allebeck P. The use of population based registers in psychiatric research. Acta Psychiatr Scand. 2009;120:386-91.

Alvarez-Lozano J, Osmani V, Mayora O, Frost M, Bardram J, Faurholt-Jepsen $\mathrm{M}$, et al. Tell me your apps and I will tell you your mood: correlation of apps usage with bipolar disorder state. In: ACM Proceedings of the 7th international conference on pervasive technologies related to assistive environments. New York: ACM; 2014. p. 19.

Arthur C. Google's growing problem: $50 \%$ of people do zero searches per day on mobile. 2015. https://www.theoverspill.wordpress.com/2015/10/19/ searches-average-mobile-google-problem/. Accessed 19 Jan 2016.

Bagalman E, Muser E, Choi JC, Durden E, Macfadden W, Haskins JT, et al. Health care resource utilization and costs in a commercially insured population of patients with bipolar disorder type I and frequent psychiatric interventions. Clin Ther. 2011;33:1381-90.

Baldessarini RJ, Leahy L, Arcona S, Gause D, Zhang W, Hennen J. Patterns of psychotropic drug prescription for U.S. patients with diagnoses of bipolar disorders. Psychiatr Serv. 2007;58:85-91.

Banaee $H$, Ahmed MU, Loutfi A. Data mining for wearable sensors in health monitoring systems: a review of recent trends and challenges. Sensors (Basel). 2013;13:17472-500.

Bauer MS, Crits-Christoph P, Ball WA, Dewees E, McAllister T, Alahi P, et al. Independent assessment of manic and depressive symptoms by self-rating. Scale characteristics and implications for the study of mania. Arch Gen Psychiatry. 1991;48:807-12.

Bauer M, Grof P, Gyulai L, Rasgon N, Glenn T, Whybrow PC. Using technology to improve longitudinal studies: self-reporting with ChronoRecord in bipolar disorder. Bipolar Disord. 2004;6:67-74.

Bauer M, Wilson T, Neuhaus K, Sasse J, Pfennig A, Lewitzka U, et al. Selfreporting software for bipolar disorder: validation of ChronoRecord by patients with mania. Psychiatry Res. 2008;159:359-66.

Bauer R, Glenn T, Alda M, Sagduyu K, Marsh W, Grof P, et al. Antidepressant dosage taken by patients with bipolar disorder: factors associated with irregularity. Int J Bipolar Disord. 2013a;1:26. 
Bauer M, Glenn T, Alda M, Sagduyu K, Marsh W, Grof P, Munoz R, et al. Drug treatment patterns in bipolar disorder: analysis of long-term selfreported data. Int J Bipolar Disord. 2013b;1:5.

Bayley KB, Belnap T, Savitz L, Masica AL, Shah N, Fleming NS. Challenges in using electronic health record data for CER: experience of four learning organizations and solutions applied. Med Care. 2013;51(8 Suppl 3):S80-6.

Berger ML, Doban V. Big data, advanced analytics and the future of comparative effectiveness research. J Comp Eff Res. 2014;3:167-76.

Bilton N. Data without context tells a misleading story. The New York Times. 2013. http://www.bits.blogs.nytimes.com/2013/02/24/disruptionsgoogle-flu-trends-shows-problems-of-big-data-without-context/? $r=0$. Accessed 19 Jan 2016.

Binder $\mathrm{H}$, Blettner M. Big data in medical science-a biostatistical view. Dtsch Arztebl Int. 2015;112:137-42.

Bjørklund L, Horsdal HT, Mors O, Østergaard SD, Gasse C. Trends in the psychopharmacological treatment of bipolar disorder: a nationwide register-based study. Acta Neuropsychiatr. 2015;11:1-10.

Blair DR, Lyttle CS, Mortensen JM, Bearden CF, Jensen AB, Khiabanian H, et al. A nondegenerate code of deleterious variants in Mendelian loci contributes to complex disease risk. Cell. 2013;155:70-80.

Bloechliger M, Rüegg S, Jick SS, Meier CR, Bodmer M. Antipsychotic drug use and the risk of seizures: follow-up study with a nested case-control analysis. CNS Drugs. 2015;29:591-603.

Bocchetta A, Ardau R, Fanni T, Sardu C, Piras D, Pani A, et al. Renal function during long-term lithium treatment: a cross-sectional and longitudinal study. BMC Med. 2015;13:12.

Bopp JM, Miklowitz DJ, Goodwin GM, Stevens W, Rendell JM, Geddes JR. The longitudinal course of bipolar disorder as revealed through weekly text messaging: a feasibility study. Bipolar Disord. 2010;12:327-34.

Boulden, J. Will artificial intelligence kill the smartphone? CNN Money. 2015. http://www.money.cnn.com/2015/12/09/technology/ericsson-surveypredicts-smartphone-death/. Accessed 19 Jan 2016.

Boyd D, Crawford K. Critical questions for big data: provocations for a cultural, technological, and scholarly phenomenon. Inf Commun Soc. 2012;15:662-79.

Brown JD, Barrett A, Caffery E, Hourihan K, Ireys HT. Medication continuity among medicaid beneficiaries with schizophrenia and bipolar disorder Psychiatr Serv. 2013;64:878-85

Brown JD, Barrett A, Hourihan K, Caffery E, Ireys HT. State variation in the delivery of comprehensive services for medicaid beneficiaries with schizophrenia and bipolar disorder. Community Ment Health J. 2015;51:523-34.

Burkhardt P. An overview of big data, vol. 20. Dayton: The Next Wave; 2014. p. $1-7$.

Butler M, Kane RL, McAlpine D, Kathol RG, Fu SS, Hagedorn H, et al. Integration of mental health/substance abuse and primary care. Evid Rep Technol Assess (Full Rep). 2008;173:1-362.

Byrne N, Regan C, Howard L. Administrative registers in psychiatric research: a systematic review of validity studies. Acta Psychiatr Scand. 2005;112:409-14.

Cai X, Li Y. Are AMI patients with comorbid mental illness more likely to be admitted to hospitals with lower quality of AMI care. PLoS One. 2013:8:e60258.

Calkin CV, Alda M. Insulin resistance in bipolar disorder: relevance to routine clinical care. Bipolar Disord. 2015;17:683-8.

Calkin CV, Ruzickova M, Uher R, Hajek T, Slaney CM, Garnham JS, et al. Insulin resistance and outcome in bipolar disorder. Br J Psychiatry. 2015;206:52-7.

Carlborg A, Ferntoft L, Thuresson M, Bodegard J. Population study of disease burden, management, and treatment of bipolar disorder in Sweden: a retrospective observational registry study. Bipolar Disord. 2015;17:76-85.

Carney CP, Jones LE. Medical comorbidity in women and men with bipolar disorders: a population-based controlled study. Psychosom Med. 2006;68:684-91.

Castro VM, Minnier J, Murphy SN, Kohane I, Churchill SE, Gainer V, et al. Validation of electronic health record phenotyping of bipolar disorder cases and controls. Am J Psychiatry. 2015;172:363-72.

Castro VM, Roberson AM, McCoy TH, Wiste A, Cagan A, Smoller JW, et al. Stratifying risk for renal insufficiency among lithium-treated patients: an electronic health record study. Neuropsychopharmacology. 2016:41(4):1138-43 (Epub ahead of print).

Cerimele JM, Strain JJ. Integrating primary care services into psychiatric care settings: a review of the literature. Prim Care Companion J Clin Psychiatry. 2010;12(6). doi:10.4088/PCC.10r00971 whi

Chan EW, Liu KQ, Chui CS, Sing CW, Wong LY, Wong IC. Adverse drug reactionsexamples of detection of rare events using databases. Br J Clin Pharmacol. 2015;80:855-61.

Chang CK, Hayes RD, Perera G, Broadbent MT, Fernandes AC, Lee WE, et al. Life expectancy at birth for people with serious mental illness and other major disorders from a secondary mental health care case register in London. PLoS One. 2011;6:e19590.

Chen W, Deveaugh-Geiss AM, Palmer L, Princic N, Chen YT. Patterns of atypical antipsychotic therapy use in adults with bipolar I disorder in the USA. Hum Psychopharmacol. 2013;28:428-37.

Clarke MC, Tanskanen A, Huttunen MO, Clancy M, Cotter DR, Cannon M. Evidence for shared susceptibility to epilepsy and psychosis: a populationbased family study. Biol Psychiatry. 2012;71:836-9.

Clemens NA. Privacy, consent, and the electronic mental health record: the person vs. the system. J Psychiatr Pract. 2012;18:46-50.

Clemente AS, Diniz BS, Nicolato R, Kapczinski FP, Soares JC, Firmo JO, et al. Bipolar disorder prevalence: a systematic review and meta-analysis of the literature. Rev Bras Psiquiatr. 2015;37:155-61.

Clos S, Rauchhaus P, Severn A, Cochrane L, Donnan PT. Long-term effect of lithium maintenance therapy on estimated glomerular filtration rate in patients with affective disorders: a population-based cohort study. Lancet Psychiatry. 2015;2:1075-83.

Close H, Reilly J, Mason JM, Kripalani M, Wilson D, Main J, Hungin AP. Renal failure in lithium-treated bipolar disorder: a retrospective cohort study. PLoS One. 2014;9(3):e90169.

Conti V, Venegoni M, Cocci A, Fortino I, Lora A, Barbui C. Antipsychotic drug exposure and risk of pulmonary embolism: a population-based, nested case-control study. BMC Psychiatry. 2015;15:92.

Conus P, Macneil C, McGorry PD. Public health significance of bipolar disorder: implications for early intervention and prevention. Bipolar Disord. 2014;16:548-56.

Coppersmith G, Dredze M, Harman C, Hollingshead K. From ADHD to SAD: analyzing the language of mental health on Twitter through self-reported diagnoses. In: Proceedings of the 2 nd workshop on computational linguistics and clinical psychology: from linguistic signal to clinical reality. Denver: North American Chapter of the Association for Computational Linguistics 2015.

Crawford K. The hidden biases in big data. Harvard Business Review. 2013. https://www.hbr.org/2013/04/the-hidden-biases-in-big-data. Accessed 19 Jan 2016.

Crump C, loannidis JP, Sundquist K, Winkleby MA, Sundquist J. Mortality in persons with mental disorders is substantially overestimated using inpatient psychiatric diagnoses. J Psychiatr Res. 2013a;47:1298-303.

Crump C, Sundquist K, Winkleby MA, Sundquist J. Comorbidities and mortality in bipolar disorder: a Swedish national cohort study. JAMA Psychiatry. 2013b;70:931-9.

Curtis M. New data sources: a conversation with Google's Hal Varian. Federal Reserve Bank of Atlanta. 2014. http://www.macroblog.typepad.com/ macroblog/2014/04/new-data-sources-a-conversation-with-googleshal-varian.html. Accessed 19 Jan 2016.

Daglas R, Yücel M, Cotton S, Allott K, Hetrick S, Berk M. Cognitive impairment in first-episode mania: a systematic review of the evidence in the acute and remission phases of the illness. Int J Bipolar Disord. 2015;25(3):9.

Davenport T. Big data at work: dispelling the myths, uncovering the opportunities. New York: Harvard Business Review Press; 2014. p. 43.

D'Agostino RB Sr, Vasan RS, Pencina MJ, Wolf PA, Cobain M, Massaro JM, et al. General cardiovascular risk profile for use in primary care: the Framingham heart study. Circulation. 2008;117:743-53.

Datta R, Li J, Wang JZ. Exploiting the human-machine gap in image recognition for designing CAPTCHAs. IEEE Trans Inf Forensics Secur. 2009:4:504-18.

Davidson M, Kapara O, Goldberg S, Yoffe R, Noy S, Weiser M. A nation-wide study on the percentage of schizophrenia and bipolar disorder patients who earn minimum wage or above. Schizophr Bull. 2016;42(2):443-7 (Epub ahead of print) 
De Hert M, Correll CU, Bobes J, Cetkovich-Bakmas M, Cohen D, Asai I, et al. Physical illness in patients with severe mental disorders. I. Prevalence, impact of medications and disparities in health care. World Psychiatry. 2011:10:52-77.

de Lissovoy G. Big data meets the electronic medical record: a commentary on "identifying patients at increased risk for unplanned readmission". Med Care. 2013;51:759-60

DeShazo JP, Hoffman MA. A comparison of a multistate inpatient EHR database to the HCUP Nationwide inpatient sample. BMC Health Serv Res. 2015; 15:384.

Dinov ID. Methodological challenges and analytic opportunities for modeling and interpreting big healthcare data. Gigascience. 2016;5:12.

Dove ES, Phillips M. Privacy law, data sharing policies, and medical data: a comparative perspective. In: Gkoulalas-Divanis A, Loukides, editors. Medical data privacy handbook. Berlin: Springer International Publishing; 2015. p. 639-78.

Druss BG, Zhao L, Von Esenwein S, Morrato EH, Marcus SC. Understanding excess mortality in persons with mental illness: 17-year follow up of a nationally representative US survey. Med Care. 2011;49:599-604.

Elgan M. The dark side of the coming chatbot revolution. Computerworld. 2015. http://www.computerworld.com/article/3018162/emergingtechnology/the-dark-side-of-the-coming-chatbot-revolution.html. Accessed 19 Jan 2016.

Experian 2015 Data Breach Industry Forecast. 2015. http://www.experian.com/ assets/data-breach/white-papers/2016-experian-data-breach-industryforecast.pdf. Accessed 19 Jan 2016.

Fan J, Han F, Liu H. Challenges of big data analysis. Natl Sci Rev. 2014;1:293-314.

Faurholt-Jepsen M, Vinberg M, Frost M, Christensen EM, Bardram JE, Kessing LV. Smartphone data as an electronic biomarker of illness activity in bipolar disorder. Bipolar Disord. 2015;17:715-28.

Fernald J, Wang B. The recent rise and fall of rapid productivity growth. Federal Reserve Bank of San Francisco Economic Letter. 2015. http://www.frbsf. org/economic-research/publications/economic-letter/2015/february/economic-growth-information-technology-factor-productivity/. Accessed 19 Jan 2016.

Fiest KM, Jette N, Quan H, St Germaine-Smith C, Metcalfe A, Patten SB, et al. Systematic review and assessment of validated case definitions for depression in administrative data. BMC Psychiatry. 2014;14:289.

Fontanella CA, Hiance-Steelesmith DL, Gilchrist R, Bridge JA, Weston D II, Campo JV. Quality of care for medicaid-enrolled youth with bipolar disorders. Adm Policy Ment Health. 2015;42:126-38.

FTC (US Federal Trade Commission). Self-regulatory principles for online behavioral advertising. 2009. https://www.ftc.gov/sites/default/files/ documents/reports/federal-trade-commission-staff-report-self-regulatory-principles-online-behavioral-advertising/p085400behavadreport. pdf. Accessed 19 Jan 2016.

Gale CR, Batty GD, McIntosh AM, Porteous DJ, Deary IJ, Rasmussen F. Is bipola disorder more common in highly intelligent people? A cohort study of a million men. Mol Psychiatry. 2013;18:190-4.

Geller T. How do you feel? Your computer knows. Commun ACM. 2014;57:24-6.

Glenn T, Monteith S. New measures of mental state and behavior based on data collected from sensors, smartphones, and the internet. Curr Psychiatry Rep. 2014a;16:523.

Glenn T, Monteith S. Privacy in the digital world: medical and health data outside of HIPAA protections. Curr Psychiatry Rep. 2014b;16:494.

Gold L, Ayers D, Bertino J, Bock C, Bock A, Brody EN, et al. Aptamer-based multiplexed proteomic technology for biomarker discovery. PLoS One. 2010;5:e15004.

Goldstein BA, Winkelmayer WC. Comparative health services research across populations: the unused opportunities in big data. Kidney Int. 2015;87:1094-6

Goldstein BI, Schaffer A, Wang S, Blanco C. Excessive and premature new-onset cardiovascular disease among adults with bipolar disorder in the US NESARC cohort. J Clin Psychiatry. 2015;76:163-9.

Grande D, Mitra N, Shah A, Wan F, Asch DA. Public preferences about secondary uses of electronic health information. JAMA Intern Med. 2013;28(173):1798-806.

Grant BF, Stinson FS, Dawson DA, Chou SP, Dufour MC, Compton W, et al. Prevalence and co-occurrence of substance use disorders and independent mood and anxiety disorders: results from the National Epidemiologic Survey on alcohol and related conditions. Arch Gen Psychiatry. 2004;61:807-16.

Grimes DA, Schulz KF. Bias and causal associations in observational research. Lancet. 2002;359:248-52.

Gruenerbl A, Osmani V, Bahle G, Carrasco JC, Oehler S, Mayora O, et al. Using smart phone mobility traces for the diagnosis of depressive and manic episodes in bipolar patients. In: ACM Proceedings of the 5 th augmented human international conference. 2014. p. 38.

Guszcza J, Richardson B. Two dogmas of big data: understanding the power of analytics for predicting human behavior. Deloitte Rev. 2014;18:161-75.

Hamalka J. The cost of storing patient records. http://www.geekdoctor. blogspot.com/2011/04/cost-of-storing-patient-records.html. Accessed 8 Mar 2016.

Hamilton JE, Passos IC, de Azevedo Cardoso T, Jansen K, Allen M, Begley CE, et al. Predictors of psychiatric readmission among patients with bipolar disorder at an academic safety-net hospital. Aust N Z J Psychiatry. 2015. doi:10.1177/0004867415605171 [Epub ahead of print].

Hampton LM, Daubresse M, Chang HY, Alexander GC, Budnitz DS. Emergency department visits by adults for psychiatric medication adverse events. JAMA Psychiatry. 2014;71:1006-14.

Hand DJ. Data, not dogma: big data, open data, and the opportunities ahead. In: Tucker A, Höppner F, Siebes A, Swift S, editors. Advances in intelligent data analysis XII. Berlin: Springer; 2013. p. 1-12.

Hardy S, Hinks P, Gray R. Screening for cardiovascular risk in patients with severe mental illness in primary care: a comparison with patients with diabetes. J Ment Health. 2013;22:42-50.

Harris GT, Lowenkamp CT, Hilton NZ. Evidence for risk estimate precision: implications for individual risk communication. Behav Sci Law. 2015;33:111-27.

Haupt DW, Rosenblatt LC, Kim E, Baker RA, Whitehead R, Newcomer JW. Prevalence and predictors of lipid and glucose monitoring in commercially insured patients treated with second-generation antipsychotic agents. Am J Psychiatry. 2009;166:345-53.

Hayes J, Prah P, Nazareth I, King M, Walters K, Petersen I, et al. Prescribing trends in bipolar disorder: cohort study in the United Kingdom THIN primary care database 1995-2009. PLoS One. 2011;6:e28725.

HCUP Databases. Healthcare cost and utilization project (HCUP_US). 2015. Rockville: Agency for Healthcare Research and Quality. http://www. hcup-us.ahrq.gov/nisoverview.jsp. Accessed 19 Jan 2016.

HealthIT.gov. A shared nationwide interoperability roadmap version 1.0. 2015 https://www.healthit.gov/policy-researchers-implementers/interoperability. Accessed 8 Mar 2016.

Hersh WR, Weiner MG, Embi PJ, Logan JR, Payne PR, Bernstam EV, et al. Caveats for the use of operational electronic health record data in comparative effectiveness research. Med Care. 2013;51(8 Suppl 3):S30-7.

Hibar DP, Westlye LT, TGM van Erp TGM, Rasmussen J, Leonardo CD, Faskowitz $J$, et al. Subcortical volumetric abnormalities in bipolar disorder. Mol Psychiatry. 2016. doi:10.1038/mp.2015.227

Hjorthøj C, Østergaard ML, Benros ME, Toftdahl NG, Erlangsen A, Andersen JT, et al. Association between alcohol and substance use disorders and all-cause and cause-specific mortality in schizophrenia, bipolar disorder, and unipolar depression: a nationwide, prospective, register-based study. Lancet Psychiatry. 2015;2:801-8.

Hoang U, Stewart R, Goldacre MJ. Mortality after hospital discharge for people with schizophrenia or bipolar disorder: retrospective study of linked English hospital episode statistics, 1999-2006. BMJ. 2011;343:d5422.

Hochster HS, Niedzwiecki D. Big data, small effects. J Clin Oncol. 2016. doi:10.1200/JCO.2015.65.8161.

Hoertel N, Limosin F, Leleu H. Poor longitudinal continuity of care is associated with an increased mortality rate among patients with mental disorders: results from the French National Health Insurance Reimbursement Database. Eur Psychiatry. 2014;29:358-64.

Horvitz E, Mulligan D. Data, privacy, and the greater good. Science. 2015;349:253-5.

Hou L, Heilbronner U, Degenhardt F, Adli M, Akiyama K, Akula N, et al. Genetic variants associated with response to lithium treatment in bipolar disorder: a genome-wide association study. Lancet. 2016;387:1085-93.

Horrigan MW. Big data: a perspective from the BLS. Amstat news. http://www. magazine.amstat.org/blog/2013/01/01/sci-policy-jan2013/. Accessed 19 Jan 2016. 
Hripcsak G, Knirsch C, Zhou L, Wilcox A, Melton G. Bias associated with mining electronic health records. J Biomed Discov Collab. 2011;6:48-52.

Hripcsak G, Albers DJ. Next-generation phenotyping of electronic health records. J Am Med Inform Assoc. 2013;20:117-21.

Huckvale K, Prieto JT, Tilney M, Benghozi PJ, Car J. Unaddressed privacy risks in accredited health and wellness apps: a cross-sectional systematic assessment. BMC Med. 2015;13:214.

IBM. IBM and partners to transform personal health with Watson and Open Cloud. 2015a. https://www-03.ibm.com/press/us/en/pressrelease/46580.wss. Accessed 19 Jan 2016.

IBM. Leading in the era of cognitive business. 2015b. https://www.thinkexchange.com/wp-content/uploads/CIO-Leadership-Exchange-eBook. pdf. Accessed 8 Mar 2016.

IHE. Integrating the healthcare enterprise (IHE). 2015. http://www.ihe.net/ Accessed 8 Mar 2016.

Insel TR. Translating scientific opportunity into public health impact: a strategic plan for research on mental illness. Arch Gen Psychiatry. 2009;66:128-33.

Insel TR. The NIMH research domain criteria (RDoC) project: precision medicine for psychiatry. Am J Psychiatry. 2014;171(4):395-7.

Ivanović M, Budimac Z. An overview of ontologies and data resources in medical domains. Expert Syst Appl. 2014;1(41):5158-66.

Jiang Y, Ni W. Estimating the impact of adherence to and persistence with atypical antipsychotic therapy on health care costs and risk of hospitalization. Pharmacotherapy. 2015;35:813-22.

Kane JM, Perlis RH, DiCarlo LA, Au-Yeung K, Duong J, Petrides G. First experience with a wireless system incorporating physiologic assessments and direct confirmation of digital tablet ingestions in ambulatory patients with schizophrenia or bipolar disorder. J Clin Psychiatry. 2013;74:e533-40.

Kaplan RM, Chambers DA, Glasgow RE. Big data and large sample size: a cautionary note on the potential for bias. Clin Transl Sci. 2014;7:342-6.

Karam ZN, Provost EM, Singh S, Montgomery J, Archer C, Harrington G, et al. Ecologically valid long-term mood monitoring of individuals with bipolar disorder using speech. In: IEEE International Conference on acoustics, speech and signal processing (ICASSP). Florence: IEEE; 2014. p. 4858-4862.

Katon WJ, Lin EH, Von Korff M, Ciechanowski P, Ludman EJ, Young B, et al. Collaborative care for patients with depression and chronic illnesses. $N$ Engl J Med. 2010;363:2611-20.

Kessing LV, Gerds TA, Feldt-Rasmussen B, Andersen PK, Licht RW. Use of lithium and anticonvulsants and the rate of chronic kidney disease: a Nationwide Population-Based Study. JAMA Psychiatry. 2015a;72:1182-91.

Kessing LV, Gerds TA, Feldt-Rasmussen B, Andersen PK, Licht RW. Lithium and renal and upper urinary tract tumors - results from a nationwide population-based study. Bipolar Disord. 2015b;17:805-13.

Kessing LV, Vradi E, Andersen PK. Life expectancy in bipolar disorder. Bipolar Disord. 2015c;17:543-8.

Kessing LV, Vradi E, McIntyre RS, Andersen PK. Causes of decreased life expectancy over the life span in bipolar disorder. J Affect Disord. 2015d;180:142-7.

Kessler RC, McGonagle KA, Zhao S, Nelson CB, Hughes M, Eshleman S, et al. Lifetime and 12-month prevalence of DSM-III-R psychiatric disorders in the United States. Results from the National Comorbidity Survey. Arch Gen Psychiatry. 1994;51:8-19.

Kleine-Budde K, Touil E, Moock J, Bramesfeld A, Kawohl W, Rössler W. Cost of illness for bipolar disorder: a systematic review of the economic burden. Bipolar Disord. 2014;16:337-53.

Khoury MJ, loannidis JP. Medicine. Big data meets public health. Science. 2014;346:1054-5

Ko J, Lu C, Srivastava MB, Stankovic J, Terzis A, Welsh M. Wireless sensor networks for healthcare. Proc IEEE. 2010;98:1947-60.

Kupka RW, Altshuler LL, Nolen WA, Suppes T, Luckenbaugh DA, Leverich GS, et al. Three times more days depressed than manic or hypomanic in both bipolar I and bipolar II disorder1. Bipolar Disord. 2007;9:531-5.

Kyaga S, Lichtenstein P, Boman M, Landén M. Bipolar disorder and leadershipa total population study. Acta Psychiatr Scand. 2015;131:111-9.

Landauer TK. The trouble with computers: usefulness, usability, and productivity, vol. 21. Cambridge: MIT press; 1995.

Larson EB. Building trust in the power of "big data" research to serve the public good. JAMA. 2013;309:2443-4.
Laursen TM, Munk-Olsen T, Nordentoft M, Mortensen PB. Increased mortality among patients admitted with major psychiatric disorders: a registerbased study comparing mortality in unipolar depressive disorder, bipolar affective disorder, schizoaffective disorder, and schizophrenia. J Clin Psychiatry. 2007;68:899-907.

Laursen TM, Munk-Olsen T, Agerbo E, Gasse C, Mortensen PB. Somatic hospital contacts, invasive cardiac procedures, and mortality from heart disease in patients with severe mental disorder. Arch Gen Psychiatry. 2009;66:713-20.

Laursen TM, Mortensen PB, MacCabe JH, Cohen D, Gasse C. Cardiovascular drug use and mortality in patients with schizophrenia or bipolar disorder: a Danish population-based study. Psychol Med. 2014;44:1625-37.

Lazer D, Kennedy R, King G, Vespignani A. The parable of Google Flu: traps in big data analysis. Science. 2014a;343:1203-5.

Lazer D, Kennedy R, King G, Vespignani A. Google flu trends still appears sick: an evaluation of the 2013-2014 flu season. 2014b. http://www.dx.doi. org/10.2139/ssrn.2408560. Accessed 19 Jan 2016.

Li X, Shen C. Linkage of patient records from disparate sources. Stat Methods Med Res. 2013;22:31-8.

Lyalina S, Percha B, LePendu P, Iyer SV, Altman RB, Shah NH. Identifying phenotypic signatures of neuropsychiatric disorders from electronic medical records. J Am Med Inform Assoc. 2013;20:e297-305.

Mabry PL, Olster DH, Morgan GD, Abrams DB. Interdisciplinarity and systems science to improve population health: a view from the NIH Office of behavioral and social sciences research. Am J Prev Med. 2008;35(2 Suppl):S211-24.

MacMillan D. Mobile search tops at google. Wall street journal. (WSJ.D). 2015. http://www.blogs.wsj.com/digits/2015/10/08/google-says-mobilesearches-surpass-those-on-pcs/. Accessed 19 Jan 2016.

Madigan D, Ryan PB, Schuemie M, Stang PE, Overhage JM, Hartzema AG, et al. Evaluating the impact of database heterogeneity on observational study results. Am J Epidemiol. 2013;178:645-51.

Mahoney MW, Lim LH, Carlsson GE. Algorithmic and statistical challenges in modern large-scale data analysis are the focus of MMDS (modern massive data sets). 2008. http://www.arxiv.org/abs/0812.3702. Accessed 19 Jan 2016.

Manderscheid R, Kathol R. Fostering sustainable, integrated medical and behavioral health services in medical settings. Ann Intern Med. 2014;160:61-5.

Mangurian C, Newcomer JW, Vittinghoff E, Creasman JM, Knapp P, FuentesAfflick $E$, et al. Diabetes screening among underserved adults with severe mental illness who take antipsychotic medications. JAMA Intern Med. 2015;175:1977-9.

Marewski JN, Gigerenzer G. Heuristic decision making in medicine. Dialogues Clin Neurosci. 2012;14:77-89.

Marketscan. Health research data for the real world: the MarketScan databases. Truven Health Analytics. 2011. http://www.truvenhealth.com/portals/0/ assets/PH_11238_0612_TEMP_MarketScan_WP_FINAL.pdf. Accessed 19 Jan 2016.

McAfee A, Brynjolfsson E, Davenport TH, Patil DJ, Barton D. Big data: the management revolution. Harvard Bus Rev. 2012;90:61-7.

McCarthy JF, Bossarte RM, Katz IR, Thompson C, Kemp J, Hannemann CM, et al. Predictive modeling and concentration of the risk of suicide: implications for preventive interventions in the US Department of Veterans Affairs. Am J Public Health. 2015;105:1935-42.

McGinty EE, Baller J, Azrin ST, Juliano-Bult D, Daumit GL. Quality of medical care for persons with serious mental illness: a comprehensive review. Schizophrenia Res. 2015;165:227-35.

McGraw D. Building public trust in uses of Health Insurance Portability and Accountability Act de-identified data. J Am Med Inform Assoc. 2013;20:29-34.

Medicaid. Medicaid.gov by population. 2015. http://www.medicaid.gov/ medicaid-chip-program-information/by-population/by-population. html. Accessed 19 Jan 2016.

Melek SP, Norris DT, Paulus J. Economic impact of integrated medical-behavioral healthcare. Milliman Am Psychiatr Assoc Rep. 2014.

Mitchell AJ, Hardy SA. Screening for metabolic risk among patients with severe mental illness and diabetes: a national comparison. Psychiatr Serv. 2013;64:1060-3.

Monteith S, Glenn T, Geddes J, Bauer M. Big data are coming to psychiatry: a general introduction. Int J Bipolar Disord. 2015;3(1):21. 
Moons KG, Kengne AP, Woodward M, Royston P, Vergouwe Y, Altman DG, et al. Risk prediction models: I. Development, internal validation, and assessing the incremental value of a new (bio) marker. Heart. 2012;98:683-90.

Moore PJ, Little MA, McSharry PE, Goodwin GM, Geddes JR. Mood dynamics in bipolar disorder. Int J Bipolar Disord. 2014;2:11.

Mortensen PB, Pedersen CB, McGrath JJ, Hougaard DM, Nørgaard-Petersen $\mathrm{B}$, Mors $\mathrm{O}$, et al. Neonatal antibodies to infectious agents and risk of bipolar disorder: a population-based case-control study. Bipolar Disord. 2011;13:624-9.

Muaremi A, Gravenhorst F, Grünerbl A, Arnrich B, Tröster G. Assessing bipolar episodes using speech cues derived from phone calls. In: Cipresso P, Lopez G, Matic A, editors. Pervasive computing paradigms for mental health. Springer; 2014. p. 103-14.

Muench F. The promises and pitfalls of digital technology in its application to alcohol treatment. Alcohol Res. 2014;36:131-42.

Munk-Jørgensen P, Okkels N, Golberg D, Ruggeri M, Thornicroft G. Fifty years' development and future perspectives of psychiatric register research. Acta Psychiatr Scand. 2014;130:87-98.

Narayanan A, Huey J, Felten EW. A precautionary approach to big data privacy. In: Gutwirth S, Leenes R, De Hert P, editors. Data protection on the move. Netherlands: Springer; 2016. p. 357-85.

Nguyen T, O'Dea B, Larsen M, Phung D, Venkatesh S, Christensen H. Differentiating sub-groups of online depression-related communities using textual cues. In: Wang J, Cellary W, Wang D, Wang H, Chen S-C, Li T, Zhang Y, editors. Web information systems engineering-WISE. Springer; 2015. p. 216-24.

NRC (National Research Council US) commititee on the analysis of massive data. Frontiers in massive data analysis. 2013. http://www.nap.edu/catalog/18374/frontiers-in-massive-data-analysis. Accessed 19 Jan 2016.

Øiesvold T, Nivison M, Hansen V, Skre I, Ostensen L, Sørgaard KW. Diagnosing comorbidity in psychiatric hospital: challenging the validity of administrative registers. BMC Psychiatry. 2013;13:13.

Øiesvold T, Nivison M, Hansen V, Sørgaard KW, Østensen L, Skre I. Classification of bipolar disorder in psychiatric hospital. A prospective cohort study. BMC Psychiatry. 2012;12:13.

Osborn DP, Hardoon S, Omar RZ, Holt RI, King M, Larsen J, et al. Cardiovascular risk prediction models for people with severe mental illness: results from the prediction and management of cardiovascular risk in people with severe mental illnesses (PRIMROSE) research program. JAMA Psychiatry. 2015;72:143-51.

Osmani V, Maxhuni A, Grünerbl A, Lukowicz P, Haring C, Mayora O. Monitoring activity of patients with bipolar disorder using smart phones. In: ACM Proceedings of international conference on advances in mobile computing and multimedia. New York: ACM; 2013. p. 85.

Overhage JM, Overhage LM. Sensible use of observational clinical data. Stat Methods Med Res. 2013;22:7-13.

Page L. Google 2013 founders letter to investors. Google. 2013. http://www. investor.google.com/corporate/2013/founders-letter.html. Accessed 19 Jan 2016.

Paksarian D, Eaton WW, Mortensen PB, Merikangas KR, Pedersen CB. A population-based study of the risk of schizophrenia and bipolar disorder associated with parent-child separation during development. Psychol Med. 2015;45:2825-37.

Patel CJ, Burford B, loannidis JP. Assessment of vibration of effects due to model specification can demonstrate the instability of observational associations. J Clin Epidemiol. 2015a;68:1046-58.

Patel R, Shetty H, Jackson R, Broadbent M, Stewart R, Boydell J, et al. Delays before diagnosis and initiation of treatment in patients presenting to mental health services with bipolar disorder. PLoS One. 2015b;10:e0126530.

Pathak J, Kho AN, Denny JC. Electronic health records-driven phenotyping: challenges, recent advances, and perspectives. J Am Med Inform Assoc. 2013;20:e206-11.

Paxton C, Niculescu-Mizil A, Saria S. Developing predictive models using electronic medical records: challenges and pitfalls. AMIA Annu Symp Proc. 2013;2013:1109-15.

Piette JD, Sussman JB, Pfeiffer PN, Silveira MJ, Singh S, Lavieri MS. Maximizing the value of mobile health monitoring by avoiding redundant patient reports: prediction of depression-related symptoms and adherence problems in automated health assessment services. J Med Internet Res. 2013;15:e118.
Poluzzi E, Raschi E, Koci A, Moretti U, Spina E, Behr ER, et al. Antipsychotics and torsadogenic risk: signals emerging from the US FDA adverse event reporting system database. Drug Saf. 2013;36:467-79.

Pope C, Halford S, Tinati R, Weal M. What's the big fuss about 'big data'? J Health Serv Res Policy. 2014;19:67-8.

Potash JB. Electronic medical records: fast track to big data in bipolar disorder. Am J Psychiatry. 2015;172:310-1.

Pottegård A, Hallas J, Jensen BL, Madsen K, Friis S. Long-term lithium use and risk of renal and upper urinary tract cancers. J Am Soc Nephrol. 2016;27:249-55.

President's council of advisors on science and technology. Big data and privacy: a technological Perspective. 2014. http://www.whitehouse.gov/ sites/default/files/microsites/ostp/PCAST/pcast_big_data_and_privacy___may_2014.pdf. Accessed 19 Jan 2016.

Redmond SJ, Lovell NH, Yang GZ, Horsch A, Lukowicz P, Murrugarra L, et al. What does big data mean for wearable sensor systems? Contribution of the IMIA wearable sensors in healthcare WG. Yearb Med Inform. 2014;9:135-42.

Reynolds CF III, Lewis DA, Detre T, Schatzberg AF, Kupfer DJ. The future of psychiatry as clinical neuroscience. Acad Med. 2009;84:446.

Riley GF. Administrative and claims records as sources of health care cost data. Med Care. 2009;47(7 Suppl 1):S51-5.

Robertson AG, Swanson JW, Frisman LK, Lin H, Swartz MS. Patterns of justice involvement among adults with schizophrenia and bipolar disorder: key risk factors. Psychiatr Serv. 2014;65:931-8.

Rodriguez EM, Staffa JA, Graham DJ. The role of databases in drug postmarketing surveillance. Pharmacoepidemiol Drug Saf. 2001;10:407-10.

Rose G. Sick individuals and sick populations. Int J Epidemiol. 2001;30:427-32.

Roshanaei-Moghaddam B, Katon W. Premature mortality from general medical illnesses among persons with bipolar disorder: a review. Psychiatr Serv. 2009;60:147-56.

Rothstein MA. Ethical issues in big data health research: currents in contemporary bioethics. J Law Med Ethics. 2015;43:425-9.

Sarrazin MS, Rosenthal GE. Finding pure and simple truths with administrative data. JAMA. 2012;307:1433-5.

Schärer LO, Krienke UJ, Graf SM, Meltzer K, Langosch JM. Validation of lifecharts documented with the personal life-chart app - a self-monitoring tool for bipolar disorder. BMC Psychiatry. 2015;15:49.

Seabury SA, Goldman DP, Kalsekar I, Sheehan JJ, Laubmeier K, Lakdawalla DN. Formulary restrictions on atypical antipsychotics: impact on costs for patients with schizophrenia and bipolar disorder in medicaid. Am J Manag Care. 2014;20:e52-60.

Selten JP, Lundberg M, Rai D, Magnusson C. Risks for nonaffective psychotic disorder and bipolar disorder in young people with autism spectrum disorder: a population-based study. JAMA Psychiatry. 2015;72:483-9.

Shine B, McKnight RF, Leaver L, Geddes JR. Long-term effects of lithium on renal, thyroid, and parathyroid function: a retrospective analysis of laboratory data. Lancet. 2015;386:461-8.

Shippee ND, Shah ND, Williams MD, Moriarty JP, Frye MA, Ziegenfuss JY. Differences in demographic composition and in work, social, and functional limitations among the populations with unipolar depression and bipolar disorder: results from a nationally representative sample. Health Qual Life Outcomes. 2011;9:90.

Simonite T. Facebook joins stampede of tech giants giving away artificial intelligence technology. MIT Technol Rev. 2015. http://www.technologyreview.com/news/544236/facebook-joins-stampede-of-techgiants-giving-away-artificial-intelligence-technology/. Accessed 19 Jan 2016.

Singh A, Nadkarni G, Gottesman O, Ellis SB, Bottinger EP, Guttag JV. Incorporating temporal EHR data in predictive models for risk stratification of renal function deterioration. J Biomed Inform. 2015;53:220-8.

Singh JP, Fazel S, Gueorguieva R, Buchanan A. Rates of violence in patients classified as high risk by structured risk assessment instruments. Br J Psychiatry. 2014;204:180-7.

Sklar P, Ripke S, Scott LJ, Andreassen OA, Cichon S, Craddock N, et al. Largescale genome-wide association analysis of bipolar disorder identifies a new susceptibility locus near ODZ4. Nat Genet. 2011;43:977-83.

Slabodkin G. IBM CEO: Watson health is 'our moonshot' in healthcare. 2015. http://www.thoughtsoncloud.com/2015/04/ibm-ceo-watson-healthis-our-moonshot-in-healthcare/. Accessed 8 Mar 2016. 
Smith A. US smartphone use in 2015. Pew research. 2015. http://www. pewinternet.org/2015/04/01/us-smartphone-use-in-2015/. Accessed 19 Jan 2016.

Smith DJ, Martin D, McLean G, Langan J, Guthrie B, Mercer SW. Multimorbidity in bipolar disorder and undertreatment of cardiovascular disease: a cross sectional study. BMC Med. 2013;11:263.

Smith DJ, Anderson J, Zammit S, Meyer TD, Pell JP, Mackay D. Childhood IQ and risk of bipolar disorder in adulthood: prospective birth cohort study. $\mathrm{Br}$ J Psychiatry Open. 2015;1:74-80.

SomaLogic. 2016. http://www.somalogic.com. Accessed 19 Jan 2016

Starren J, Williams MS, Bottinger EP. Crossing the omic chasm: a time for omic ancillary systems. JAMA. 2013;309:1237-8.

Stewart R, Soremekun M, Perera G, Broadbent M, Callard F, Denis M, et al. The South London and Maudsley NHS Foundation Trust Biomedical Research Centre (SLAM BRC) case register: development and descriptive data. BMC Psychiatry. 2009;9:51.

Sung I. The impact of health care reform on insurance switching patterns. Athenahealth. 2015. http://www.athenahealth.com/blog/2015/07/16/ acaview-research-brief-the-impact-of-health-care-reform-on-insurance-switching-patterns. Accessed 19 Jan 2016.

Thomas D. Smartphone makers look to other products s saturation looms. Financial Times. 2014. http://www.ft.com/cms/s/0/ed881b3a-f48711e3-a143-00144feabdc0.html. Accessed 19 Jan 2016.

Thompson PM, Stein JL, Medland SE, Hibar DP, Vasquez AA, Renteria ME, et al. The ENIGMA Consortium: large-scale collaborative analyses of neuroimaging and genetic data. Brain Imaging Behav. 2014;8:153-82.

Tournier M. Current antipsychotic drug treatment may increase the risk of pulmonary embolism. Evid Based Ment Health. 2015;18:115.

Townsend L, Walkup JT, Crystal S, Olfson M. A systematic review of validated methods for identifying depression using administrative data. Pharmacoepidemiol Drug Saf. 2012;21(Suppl 1):163-73.

Valenza G, Nardelli M, Lanata A, Gentili C, Bertschy G, Paradiso R, et al. Wearable monitoring for mood recognition in bipolar disorder based on historydependent long-term heart rate variability analysis. IEEE J Biomed Health Inform. 2014;18:1625-35.

Varian HR. Beyond big data. Bus Econ. 2014;49:27-31.

Vigod SN, Kurdyak PA, Seitz D, Herrmann N, Fung K, Lin E, et al. READMIT: a clinical risk index to predict 30-day readmission after discharge from acute psychiatric units. J Psychiatr Res. 2015;61:205-13.

Wang X, Wang F, Hu J, Sorrentino R. Exploring joint disease risk prediction. AMIA Annu Symp Proc. 2014;2014:1180-7.

Ware $\mathrm{JH}$. The limitations of risk factors as prognostic tools. N Engl J Med. 2006;355:2615-7.

Waters R. Tech firms have high hopes for new year. Financial times. 2015. http://www.ft.com/cms/s/0/c7da2042-77ce-11e5-a95a-27d368e1ddf7. html\#axzz3v6YjTcW2. Accessed 19 Jan 2016.

Webb RT, Lichtenstein P, Larsson H, Geddes JR, Fazel S. Suicide, hospitalpresenting suicide attempts, and criminality in bipolar disorder: examination of risk for multiple adverse outcomes. J Clin Psychiatry. 2014;75:e809-16.
West SL, Johnson W, Visscher W, Kluckman M, Qin Y, Larsen A. The challenges of linking health insurer claims with electronic medical records. Health Informatics J. 2014;20:22-34.

Westman J, Hällgren J, Wahlbeck K, Erlinge D, Alfredsson L, Osby U. Cardiovascular mortality in bipolar disorder: a population-based cohort study in Sweden. BMJ Open. 2013;3(4):e002373. doi:10.1136/ bmjopen-2012-002373

Wharam JF, Weiner JP. The promise and peril of healthcare forecasting. Am J Manag Care. 2012;18:e82-5.

Wilson J, Bock A. The benefit of using both claims data and electronic medical record data in health care analysis. Eden Prairie MN: Optum; 2012. https://www.optum.com/content/dam/optum/resources/whitePapers/Benefits-of-using-both-claims-and-EMR-data-in-HC-analysisWhitePaper-ACS.pdf. Accessed 19 Jan 2016.

Wium-Andersen MK, Ørsted DD, Nordestgaard BG. Elevated C-reactive protein and lateonset bipolar disorder in 78,809 individuals from the general population. Br J Psychiatry. 2015;208(2):138-45 (Epub ahead of print).

Woltmann E, Grogan-Kaylor A, Perron B, Georges H, Kilbourne AM, Bauer MS. Comparative effectiveness of collaborative chronic care models for mental health conditions across primary, specialty, and behavioral health care settings: systematic review and meta-analysis. Am J Psychiatry. 2012;169(8):790-804.

Wotton CJ, Goldacre MJ. Record-linkage studies of the coexistence of epilepsy and bipolar disorder. Soc Psychiatry Psychiatr Epidemiol. 2014;49:1483-8.

Wray NR, Yang J, Hayes BJ, Price AL, Goddard ME, Visscher PM. Pitfalls of predicting complex traits from SNPs. Nat Rev Genet. 2013;14:507-15.

Wu J, Roy J, Stewart WF. Prediction modeling using EHR data: challenges, strategies, and a comparison of machine learning approaches. Med Care. 2010;48(6 Suppl):S106-13.

Wu SI, Chen SC, Juang JJ, Fang CK, Liu SI, Sun FJ, et al. Diagnostic procedures, revascularization, and inpatient mortality after acute myocardial infarction in patients with schizophrenia and bipolar disorder. Psychosom Med. 2013;75:52-9.

Wyss R, Stürmer T. Commentary: balancing automated procedures for confounding control with background knowledge. Epidemiology. 2014;25:279-81.

Yang SY, Liao YT, Liu HC, Chen WJ, Chen CC, Kuo CJ. Antipsychotic drugs, mood stabilizers, and risk of pneumonia in bipolar disorder: a nationwide case-control study. J Clin Psychiatry. 2013;74:e79-86.

Young AH, Rigney U, Shaw S, Emmas C, Thompson JM. Annual cost of managing bipolar disorder to the UK healthcare system. J Affect Disord. 2011;133:450-6.

Zhang Y, Adams AS, Ross-Degnan D, Zhang F, Soumerai SB. Effects of prior authorization on medication discontinuation among medicaid beneficiaries with bipolar disorder. Psychiatr Serv. 2009;60:520-7.

\section{Submit your manuscript to a SpringerOpen ${ }^{\ominus}$ journal and benefit from:}

- Convenient online submission

- Rigorous peer review

- Immediate publication on acceptance

- Open access: articles freely available online

- High visibility within the field

- Retaining the copyright to your article

Submit your next manuscript at springeropen.com 